\title{
Drying of a cellulose II gel: effect of physical modification and redispersibility in water
}

\author{
Marco Beaumont $\mathbb{D} \cdot$ Jakob König $\cdot$ Martina Opietnik $\cdot$ Antje Potthast $\cdot$ Thomas Rosenau $\mathbb{C}$
}

Received: 12 October 2016/Accepted: 15 December 2016/Published online: 2 January 2017

(C) The Author(s) 2017. This article is published with open access at Springerlink.com

\begin{abstract}
The agglomeration of cellulosic materials upon drying, often called hornification, causes a reduction of water retention, among other undesired effects. It is one of the main issues in industrial cellulose processing, especially with regard to nanocelluloses. As a consequence, high transportation and storage costs arise since nanocelluloses need to remain in aqueous suspensions unless trade-offs in reactivity, redispersibility and surface properties are accepted. In this study, different drying strategies for TENCEL $^{\circledR}$ gel, a nanostructured gel derived from the Lyocell process consisting of spherical particles, are compared and evaluated. First, freeze-drying with
\end{abstract}

Electronic supplementary material The online version of this article (doi:10.1007/s10570-016-1166-9) contains supplementary material, which is available to authorized users.

M. Beaumont · J. König · A. Potthast · T. Rosenau Division of Chemistry of Renewable Resources, Department of Chemistry, University of Natural Resources and Life Sciences Vienna (BOKU), KonradLorenz-Straße 24, 3430 Tulln, Austria

M. Opietnik

Lenzing AG, Werkstraße 2, 4860 Lenzing, Austria

T. Rosenau

Johan Gadolin Process Chemistry Centre, Åbo Akademi

University, Porthansgatan 3, 20500 Åbo/Turku, Finland

T. Rosenau ( $\square)$

1190 Vienna, Austria

e-mail: thomas.rosenau@boku.ac.at consideration of the influence of freezing temperature and the use of tert-butanol as cryo-protectant, and second, simple oven-drying at $60{ }^{\circ} \mathrm{C}$. Surprisingly, oven-dried xerogels showed higher water retention values and also better colloidal stability than the cryogels. This is in stark contrast to cellulose nanofibrils for which freeze-drying has been shown to be significantly superior to oven drying in terms of redispersibility. For the TENCEL ${ }^{\circledR}$ gel, oven-drying was thus selected and the influence of additives on the redispersibility of the cellulose II gel was studied by means of the common water retention value, particle size, colloidal stability, appearance of the redispersed gel and viscosity. The addition of the polysaccharides carboxymethyl cellulose or xanthan showed the most promising results with regard to redispersibility. Also sucrose and ammonium bicarbonate provided higher colloidal stabilities than that of the untreated TENCEL $^{\circledR}$ gel. The redispersibility of the cellulose II xerogels could thus be significantly improved by simple and cost-efficient mixing with additives prior to drying.

Keywords Cellulose - Nanocellulose - Drying · Hornification · Redispersibility · Cellulose II gel · TENCEL $^{\circledR}$
Abbreviations
$\mathrm{CNF}$
Cellulose nanofibrils
WRV
Water retention value 
DS Degree of substitution

FD Freeze drying (lyophilization)

CMC Carboxymethyl cellulose

tert-BuOH tert-butyl alcohol

\section{Introduction}

Hornification has been known for long in paper technology as a summarizing description of negative effects occurring upon the exposure of cellulosespulps, fibers, papers - to mostly thermal stress or drying. Having been introduced already in 1944 (Jayme 1944) and thus being around for some 80 years, the term is still somewhat ill-defined and open to interpretation. It is mostly seen as decrease of water retention and swelling of the cellulosic materials due to physico-chemical effects upon drying (Jayme 1944; Weise et al. 1996; Hubbe et al. 2007). Water removal and heat application (Weise et al. 1996) cause a decrease of external surface areas, closure of pores (Hubbe et al. 2007), shrinkage, and finally formation of internal, i.e. inter-cellulose, hydrogen bonds (Smook 1990). The negative consequences of such processes are manifold, and their discussion depends on the viewpoint of the application: while production of cellulose derivatives or rayon fibers will pay more attention to chemical reactivity, paper applications are more linked to parameters of cellulose-water interactions. In general, hornification is more pronounced for celluloses with delicate surface structures (highly porous or highly structured materials) and during all processes that involve removal of water directly interacting with (H-bonded to) the cellulose surface.

This way, drying of nano-structured celluloses is especially prone to cause hornification effects. Upon redispersion of dried cellulose, significantly more energy is required to defibrillate hornified fibers into cellulose nanofibrils (CNF) (Kekäläinen et al. 2014). Nano-structured celluloses, such as CNF (Eichhorn et al. 2009; Klemm et al. 2011) or TENCEL ${ }^{\circledR}$ gel $^{1}$ (Männer et al. 2015; Beaumont et al. 2016c), possess high surface areas above $250 \mathrm{~m}^{2} / \mathrm{g}$ (Cai et al. 2014; Nemoto et al. 2015; Beaumont et al. 2016a); and strong interactions between the individual colloidal particles occur during drying (Eyholzer et al. 2010;

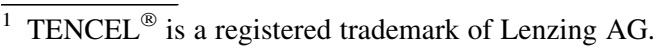

Lavoine et al. 2012). The materials are usually handled never-dried to exclude the hornification effects, but this causes high transportation and storage costs as well as a limited shelf life due to the risk of bacterial contamination (Tingaut et al. 2011). As a consequence, it is important to address this issue with the aim to find appropriate methods to increase the redispersibility of these nanomaterials in water, or in other words to limit the hornification effects during drying.

Considering nanocelluloses, freeze-drying has already proved to be a suitable method to obtain porous cryogels with good swelling and water retention properties (Han et al. 2013; Jiang and Hsieh 2014a). In general, the main issue of freeze-drying is the formation of ice crystals within the materials during the pre-freezing procedure before the lyophilization step. The formed ice crystals expand and influence the structure of the resulting cryogel. Dependent on the conditions applied the morphology can be changed from an open-porous, aerogel-like structure to a more dense, sheet-like structure (Beaumont et al. 2016c). In order to reduce this ice templating effect, faster freezing procedures or the addition of cryo-protectants, such as sucrose, may be applied (Rey and May 2011). Additionally, tert-BuOH can be applied, either added to the aqueous suspension or replacing the water completely, to obtain more porous cryogels from nanostructured celluloses featuring higher surface areas and less agglomerated structures than without solvent addition (Jiang and Hsieh 2014b; Nemoto et al. 2015; Beaumont et al. 2016c).

Apart from freeze-drying, also the effect of additives on oven-drying and air-drying has been well investigated. The adsorption of carboxymethyl cellulose onto CNF minimized the drying effects of ovendrying at $80{ }^{\circ} \mathrm{C}$ (Butchosa and Zhou 2014), yielding a water-redispersible sample with rheological and mechanical properties very similar to never-dried CNF. The influence of salts and small saccharides on the re-swelling behavior and shape memory effect of air-dried bacterial cellulose was investigated as well (Müller et al. 2014) showing the best re-swelling behavior for $\mathrm{MgCl}_{2}$ as the additive, followed by glucose and sucrose.

In contrast to the previous approaches that used only additives, redispersibility can also be brought about by chemical modification of cellulose, e.g. by 
introducing anionic charges that repel each other and prevent agglomeration, e.g. through carboxymethylation (Eyholzer et al. 2010). In the case of TENCEL ${ }^{\circledR}$ gel, however, carboxymethylation is greatly affecting the physical properties, since the particle sizes of the colloids decrease from micro-scale to nano-scale (Beaumont et al. 2016b). Hence, chemical modification does not appear to be an appropriate method in this case to increase redispersibility without changing the properties of the never-dried gel. The non-modified TENCEL ${ }^{\circledR}$ gel is a highly homogeneous suspension consisting of spherical cellulose II microparticles (Beaumont et al. 2016c). This particle-like morphology, which distinguishes it from other nanocelluloses, such as cellulose nanocrystals or nanofibrils, is to be maintained as largely as possible throughout drying and redispersion. On the nano-scale, the individual particles feature a fibrillar nanostructure with a high specific surface area and reactivity (Hettegger et al. 2016; Beaumont et al. 2016c). In this study, we compared the effects of freeze-drying and oven-drying on the redispersibility of TENCEL ${ }^{\circledR}$ gel. The different methods are evaluated by comparing the water retention value, colloidal stability, particle size and viscosity of the samples redispersed in aqueous medium.

\section{Experimental}

TENCEL $^{\circledR}$ gel with a solid content of approx. $4 \%$ was provided as purified suspension by Lenzing $A G$ and was stored at $8{ }^{\circ} \mathrm{C}$. tert- $\mathrm{BuOH}$ (puriss. p.a.) was obtained from Carl Roth. All other solvents and additives were purchased from Sigma-Aldrich. Food grade xanthan (GRINDSTED ${ }^{\circledR}$ Xanthan 80) was obtained from DuPont Danisco. Carboxymethyl cellulose (Walocel CRT 30,000 Pa) with a degree of substitution of $0.82-0.95$ was acquired from Dow Chemical.

Materials and methods

\section{Preparation of alcogels for freeze-drying}

TENCEL $^{\circledR}$ gel-tert-BuOH suspensions were prepared by centrifugation of the aqueous suspensions at $4000 \mathrm{~g}$ for $5 \mathrm{~min}$ and removal of the supernatant $\mathrm{H}_{2} \mathrm{O}$. tert-BuOH was added to the partially dewatered cellulose to a two times higher volume compared to the starting volume and the tubes were kept shaking overnight. The suspension was centrifuged once more at $4000 \mathrm{~g}$ for $5 \mathrm{~min}$ and the concentration of tert$\mathrm{BuOH}$ was adjusted the solid content to $1 \mathrm{wt} \%$, before shaking was continued overnight.

\section{Preparation of additive samples}

The additives were added to TENCEL ${ }^{\circledR}$ gel (4.2 wt $\left.\%\right)$ or CNF $(0.92 \mathrm{wt} \%)$ using the same protocol. The additives were added into a $20 \mathrm{~mL}$ glass vial and the cellulose gels were added in a ratio of $4: 1(\mathrm{w} / \mathrm{w})$. The mixtures were blended using a IKA Ultra-Turrax $\mathrm{T} 8$ at $25,000 \mathrm{rpm}$ for $30 \mathrm{~s}$ and subsequently dried at $60{ }^{\circ} \mathrm{C}$.

\section{Oven-drying}

All samples were dried in an oven at $60{ }^{\circ} \mathrm{C}$ to constant weight.

\section{Freeze-drying}

For all tests a Christ Beta 1-8 LD Plus freeze-dryer was used. Various preparation methods prior to freezedrying were used dependent on the samples. The samples ( $1 \mathrm{wt} \%$ solid content) were pre-frozen in aluminum molds at $-20,-80{ }^{\circ} \mathrm{C}$ or in liquid nitrogen $\left(-196{ }^{\circ} \mathrm{C}\right)$. The frozen samples were transferred to the lyophilizer. Additionally, samples were directly lyophilized without pre-freezing. All samples remained in the freeze-dryer for at least $72 \mathrm{~h}$.

\section{Redispersion}

Suspensions (CNF or TENCEL ${ }^{\circledR}$ gel) with a solid content of $1 \mathrm{wt} \%$ were prepared by adding $0.1 \mathrm{~g}$ of dried material to $10 \mathrm{~mL}$ of deionized $\mathrm{H}_{2} \mathrm{O}$. The samples were shaken overnight and redispersed using an IKA Ultra-Turrax T8 at 25,000 rpm until no visible agglomerates remained.

\section{Colloidal stability}

The redispersed samples were left standing in a $12 \mathrm{~mL}$ vial for $3 \mathrm{~h}$. No significant change of settlement occurred after this time. The height of the lower, cellulose-rich phase (interface height) and the total height were measured. The colloidal stability is 
defined as the interface height divided by the total height, according to Eq. 1.

Colloidal stability $=\frac{\text { Interface height }(\mathrm{mm})}{\text { Total height }(\mathrm{mm})} \times 100 \%$

\section{Water retention value}

The WRV of all redispersed samples was determined in triplicate according to Saito et al. (2007). Empty centrifugation tubes $(50 \mathrm{~mL})$ were dried at $105{ }^{\circ} \mathrm{C}$ and weighted to determine $\mathrm{m}_{0} .3 \mathrm{~mL}$ of the redispersed samples ( $1 \mathrm{wt} \%$ solid content) were added and centrifuged at $4000 \mathrm{~g}$ for $10 \mathrm{~min}$. The supernatant was removed by decantation. Residual water droplets in the tubes were carefully removed with a paper tissue before weighing the centrifugation tubes to determine $\mathrm{m}_{\text {wet. }}$. The samples were dried at $105^{\circ} \mathrm{C}$ to constant weight $\left(\mathrm{m}_{\mathrm{dry}}\right)$. The WRV $(\mathrm{g} / \mathrm{g})$ was calculated according to Eq. 2.

$\mathrm{WRV}=\frac{\left(\mathrm{m}_{\mathrm{wet}}-\mathrm{m}_{0}\right)-\left(\mathrm{m}_{\mathrm{dry}}-\mathrm{m}_{0}\right)}{\mathrm{m}_{\mathrm{dry}}-\mathrm{m}_{0}}$

\section{Particle size measurement}

The mean particles size and the particle size distribution was determined only for TENCEL ${ }^{\circledR}$ gel samples. Redispersed TENCEL ${ }^{\circledR}$ gel samples were used for the measurements. The measurement was performed on a laser diffraction particle size analyzer LS 13320 from Beckman Coulter. The pump speed was set to $70 \%$. Three runs of $60 \mathrm{~s}$ per sample were performed.

\section{Optical microscopy}

Redispersed CNF and TENCEL ${ }^{\circledR}$ gel samples were observed by optical microscopy on an incident light microscope (Axioplan 2 imaging, Carl Zeiss Microimaging $\mathrm{GmbH}$, Jena, Germany), at magnifications of $100 \times$ and $500 \times$.

\section{Scanning electron microscopy (SEM)}

Freeze-dried samples of TENCEL ${ }^{\circledR}$ gel were studied with SEM on a FEI INSPECT S50 instrument (Hillsboro, Oregon, USA). Sputtering of the samples with a gold layer of $8 \mathrm{~nm}$ thickness was performed in a Leica EM SCD005 sputter coater beforehand. Micrographs were obtained at magnifications of $500 \times$, $2000 \times, 5000 \times, 10000 \times$ and $50000 \times$ in high-vacuum mode.

\section{Results and discussion}

In the first part of this paper, different freeze-drying protocols for the cellulose II gel are compared. The structure of the different samples from electron microscopy was compared. Redispersion was evaluated by colloidal stability of the redispersed cryogels (settlement after $3 \mathrm{~h}$ ) and the ability to swell and retain water (water retention value). The properties of redispersed samples were compared to a sample oven-dried at $60{ }^{\circ} \mathrm{C}$ and to the never-dried reference.

Freeze-drying

All cryogels were obtained from $1 \mathrm{wt} \%$ suspensions. Figure 1 shows the influence of the pre-freezing temperature on the cellulose cryogels. Pre-freezing at $-20{ }^{\circ} \mathrm{C}$ caused the formation of sheet-like structures, with pores largely been lost. A decrease of the pre-freezing temperature (FD -80 and $-196{ }^{\circ} \mathrm{C}$ ) resulted in more particle-like and porous structures.

Direct freeze-drying without pre-freezing (FD vacuum) resulted in morphology in between the structures of $\mathrm{FD}-20{ }^{\circ} \mathrm{C}$ and $\mathrm{FD}-80{ }^{\circ} \mathrm{C}$. Freezing of the sample "FD vacuum" occurred due to cooling through solvent evaporation under high vacuum. The templating effect of the ice crystals is in this case was less severe than in sample FD $-20{ }^{\circ} \mathrm{C}$ (see Fig. 1), indicating that the freezing occured faster in the former sample than in the $-20{ }^{\circ} \mathrm{C}$ case.

The SEM micrographs of pre-frozen samples pictured in Fig. 1 show structures induced by ice crystal formation during the pre-freezing process of the hydrogels. As a consequence they differ greatly from the real nano- and microstructure of the cellulose II gel (Beaumont et al. 2016c). The lower the pre-freezing temperature, the more porous and less agglomerated are the respective cryogel structures.

The influence of $0.2 \mathrm{wt} \%$ sucrose [m(sucrose): $\mathrm{m}$ (cellulose), 1:4] as cryoprotectant and of tert $-\mathrm{BuOH}$ 


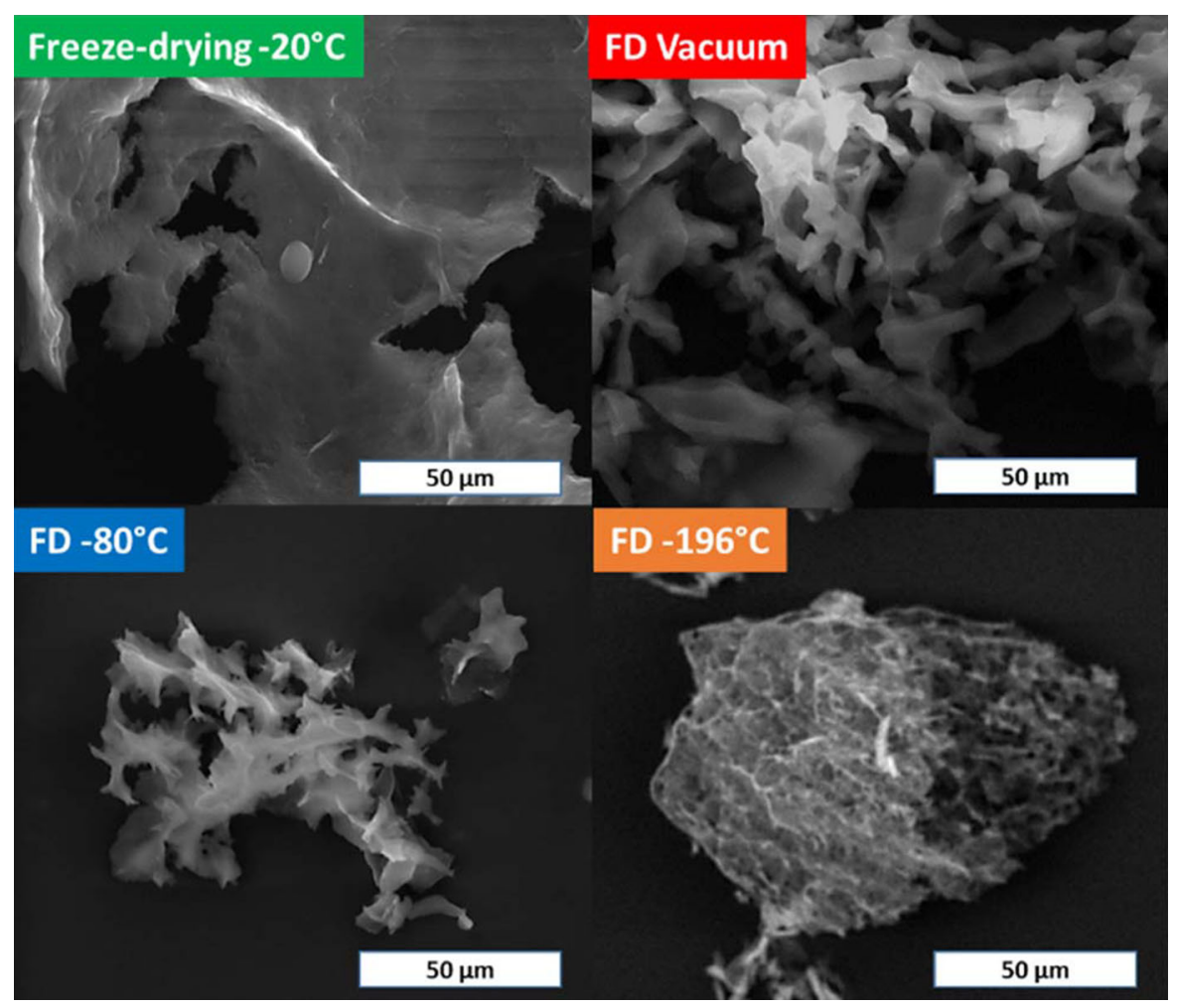

Fig. 1 SEM micrographs of TENCEL ${ }^{\circledR}$ gel cryogels using different freezing conditions. FD Vacuum was freeze-dried without prior pre-freezing. All samples were pre-frozen with

addition as dispersion medium are shown in Fig. 2. All samples were pre-frozen under the same conditions at $-20{ }^{\circ} \mathrm{C}$.

It was obvious that the addition of both tert $-\mathrm{BuOH}$ and sucrose affected the cryogel structure. In both cases the morphology was more particle-like. FD 50\% tert-BuOH and FD sucrose featured a similar microstructure, but the nanostructure was influenced by ice crystal formation and was smooth and nonporous. In order to preserve the nanostructure, it was mandatory to solvent-exchange the aqueous phase to tert-BuOH completely. Freeze-drying of the resulting alcogel yielded a very fine particle-like structure and a preserved nanostructure (see zoom in Fig. 2). In general, changes in freezing temperature and the addition of sucrose and tert-BuOH had a surprisingly pronounced influence on the cryogels' morphology. In comparison to the strongly entangled CNF, the particle-like structure of the cellulose II gel is more responsive to lyophilization conditions and amenable to the effect of additives, as shown in Fig. S1.
$1 \mathrm{wt} \%$ solid content. The aggregate size reduced and the porosity increased with lower freezing temperatures

The redispersibility of the cryogels was estimated by measuring the water retention value of the respective samples and their colloidal stability. The colloidal stability was determined by relating the settlement of a dried and redispersed sample to the never-dried gel reference, which is stable and does not phase-separate.

Both properties are compared to oven-dried gel and never-dried reference in Fig. 3. Considering the WRV, all cryogels retained less water than the never-dried sample. In addition to that, the oven-dried sample featured a higher or similar WRV than the cryogels. The colloidal stability of the cryogels increased with decreasing freezing temperatures and increasing amount of tert-BuOH. Only the redispersed sample "FD sucrose" was more stable than the ovendried sample. These findings were rather surprising especially in comparison to freeze-drying of CNF yielding cryogels with high surface area and water retention (Han et al. 2013; Jiang and Hsieh 2014a; Cai et al. 2014; Jiang and Hsieh 2014b; Nemoto et al. 2015). Redispersed CNF cryogels all formed 


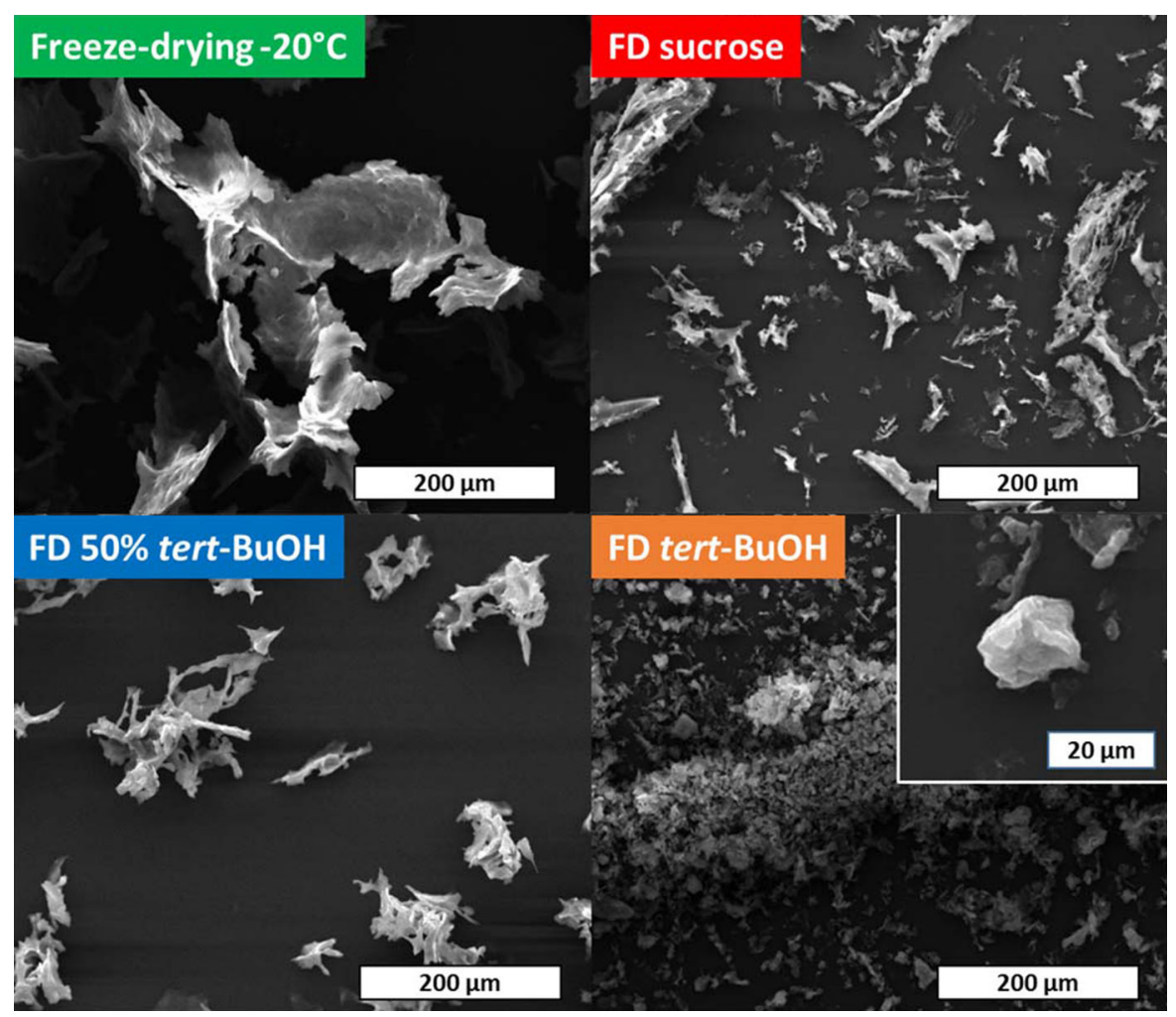

Fig. 2 Influence of sucrose and tert-BuOH during freezedrying on the morphology of cryogels in comparison to the freeze-dried aqueous sample. All solvogels were pre-frozen at $-20{ }^{\circ} \mathrm{C}$ with a solid content of $1 \mathrm{wt} \%$. The higher the amount of tert- $\mathrm{BuOH}$ the better the micro- and nanostructure is preserved as shown in the zoom of the completely solvent-exchanged FD tert-BuOH
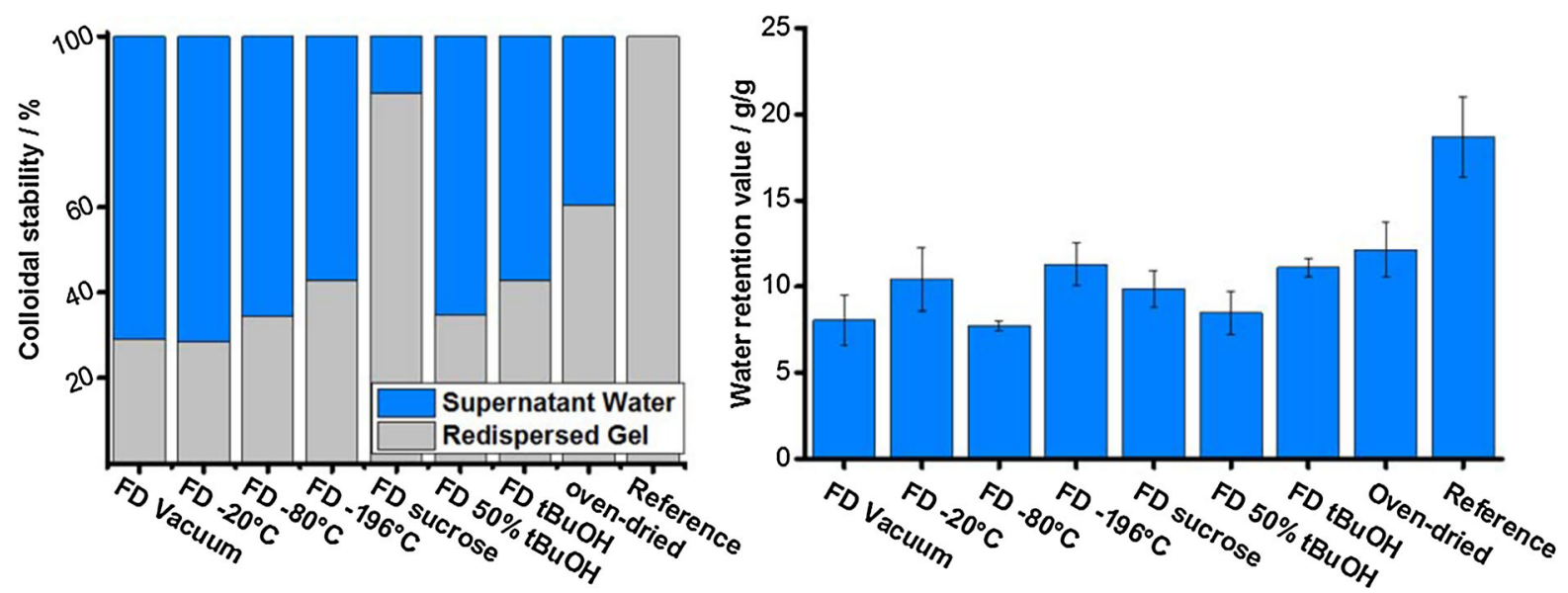

Fig. 3 Left: colloidal stability of freeze-dried sample in water after redispersion to a concentration of 1 wt $\%$. Right: water retention values of the redispersed cryogels. The oven-dried sample is listed as comparison, and the reference is the never-dried gel

stable suspensions (100\% colloidal stability) and the water retention values of the redispersed cryogels were all higher than the oven-dried sample as shown in
Fig. S2. This confirmed again that the entangled CNF network was more resistant towards freeze-drying influences than the particle-like TENCEL ${ }^{\circledR}$ gel. 
This beneficial effect of sucrose is caused by a reduction of irreversible agglomeration upon drying due to incorporation of sucrose inside the cryogel. As shown in Fig. 6 it also increased the redispersibility to a similar extent if used as additive in oven-drying. Taking this into account, there was no benefit of freeze-drying for TENCEL ${ }^{\circledR}$ gel in terms of redispersibility, especially if one considers that freezedrying is more time-consuming and costly than ovendrying. As a consequence, oven-drying was selected as method of choice and was further studied with regard to the effect of various additives on the structure and redispersibility of the samples.

\section{Oven-drying}

All samples were dried at $60{ }^{\circ} \mathrm{C}$ to constant weight. In comparison to the standard cellulose drying condition at $105{ }^{\circ} \mathrm{C}$, drying at $60{ }^{\circ} \mathrm{C}$ was chosen since it is milder and hornification effects are reduced (Giacomozzi and Joutsimo 2015).

In order to improve redispersibility, additives were added beforehand (20 wt $\%$ based on dry weight) and the mixture was homogenized with an Ultra-Turrax to ensure an even distribution of the additive inside the samples. As shown in Table S1, a variety of additives was investigated and a pre-selection was made by comparing the colloidal stability and the water retention value of the redispersed samples. Literature references of studied additives with different cellulosic materials are also listed in this table.

Figure 4 compares the microscopic images of differently dried and redispersed xerogels with the never-dried sample. The redispersed freeze-dried sample pre-frozen at $-20{ }^{\circ} \mathrm{C}$ showed the biggest agglomerates, whereas the redispersed oven-dried sample consisted of smaller particles, which were more similar to the never-dried reference. The sample containing xanthan as the additive was very alike to the never-dried reference. The samples were examined by particle size distribution (Fig. 5) of the redispersed specimen using laser diffraction size analysis.

The never-dried gel featured a homogenous particle size distribution with the main particle population between 3 and $92 \mu \mathrm{m}$ and a small particle fraction (less than $2 \mathrm{v} \%$ ) at $128 \mu \mathrm{m}$. The oven-dried sample without additive gave more heterogeneous and broader particle size distributions. The use of polymeric additives, such as xanthan and CMC, was most promising with respect to unchanged particle size distributions. Both particle size distributions were homogeneous and narrow and well comparable to the never-dried gel. The size distributions in the case of both polysaccharide additives were shifted to smaller particle sizes, and this effect was more pronounced in case of the additive xanthan. In contrast to that, samples with addition of small organic compounds (urea and sucrose) and ammonium bicarbonate showed size distributions similar to the oven-dried sample without additive.

This observation was also confirmed by measurements of the water retention value and the colloidal stability of the samples (Fig. 6). With regard to WRV and colloidal stability, the polysaccharides xanthan and CMC stuck out. As shown in Fig. S3 three carboxymethyl celluloses were compared with different degree of substitutions and viscosities in solution. The carboxymethyl cellulose with a DS of 0.82-0.95 (Walocel 2000 and 30,000 Pa) increased the WRV of the redispersed sample to a higher extent than the CMC with a DS of 0.7. The results achieved with Walocel CRT 30,000 $\mathrm{Pa}$ are shown in this study and the additive is abbreviated as CMC.

Both xanthan and CMC increased the WRV in comparison to the oven-dried reference $(12 \mathrm{~g} / \mathrm{g})$. The sample containing xanthan even featured a more than three times higher WRV (39 g/g) than the oven-dried reference, while the sample with CMC (16 g/g) had a WRV that was comparable to the never-dried gel $(18 \mathrm{~g} / \mathrm{g})$. The colloidal stability was high in both cases. In the case of the sample containing ammonium bicarbonate $\left(\mathrm{NH}_{4} \mathrm{HCO}_{3}\right)$ and sucrose the colloidal stabilities were equally good. The other additives ( $\mathrm{NaCl}, \mathrm{PEG}$ and urea) featured colloidal stabilities comparable to the oven-dried sample without additive. Considering the WRV (Fig. 6), all additives except of $\mathrm{NaCl}$ increased the WRV in comparison to the ovendried reference rather moderately. Only the addition of xanthan yielded significantly higher water retention values than the reference.

The viscosity versus shear rate of the redispersed sample w/o additive and the samples with urea and PEG are compared to the never-dried cellulose II gel in Fig. 7a. Due to the large influence of xanthan and CMC on the samples' viscosity, these two redispersed samples are separately compared to the never-dried mixtures of the gel and the respective additive (see Fig. 7b). In all samples the viscosity decreased with 


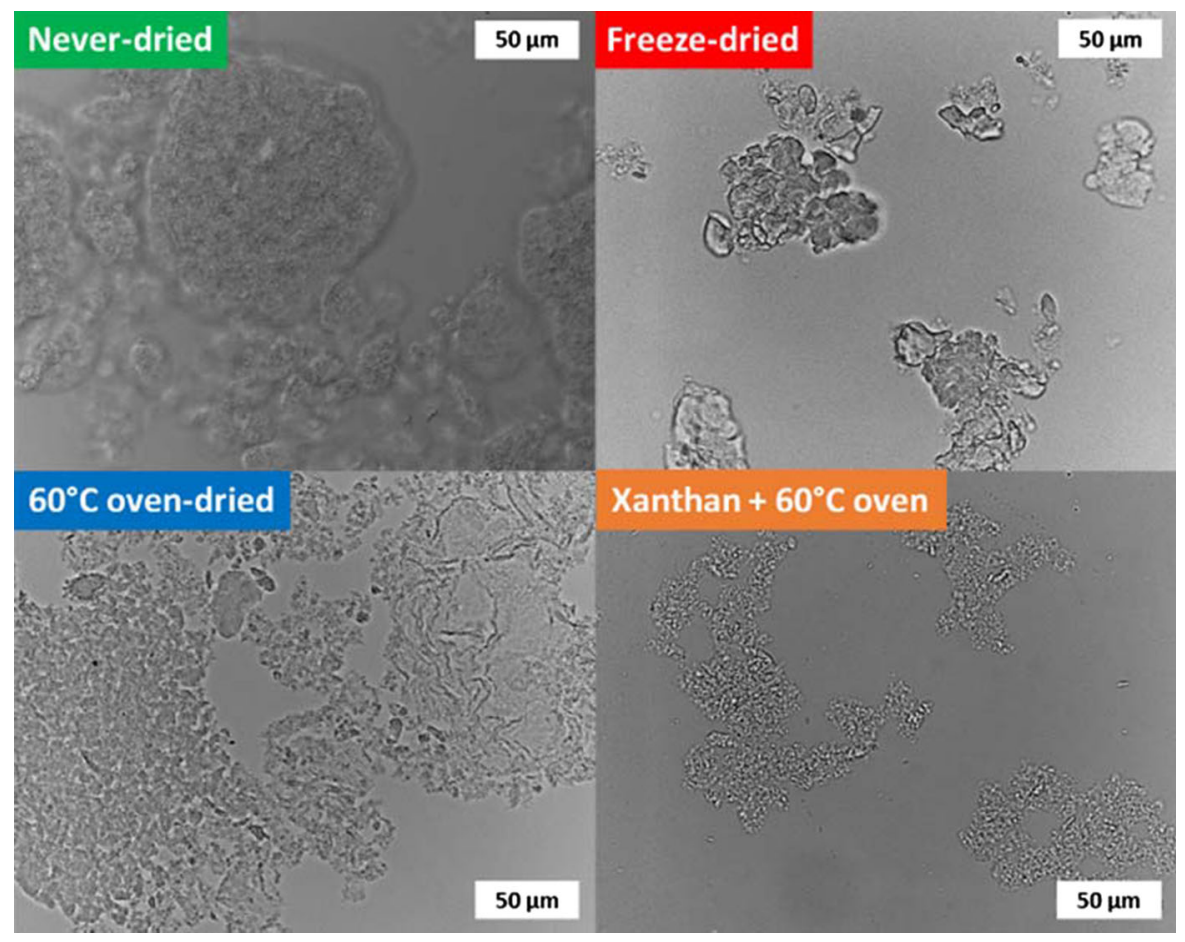

Fig. 4 Light microscope images of redispersed TENCEL ${ }^{\circledR}$ gel: a comparison of different drying protocols

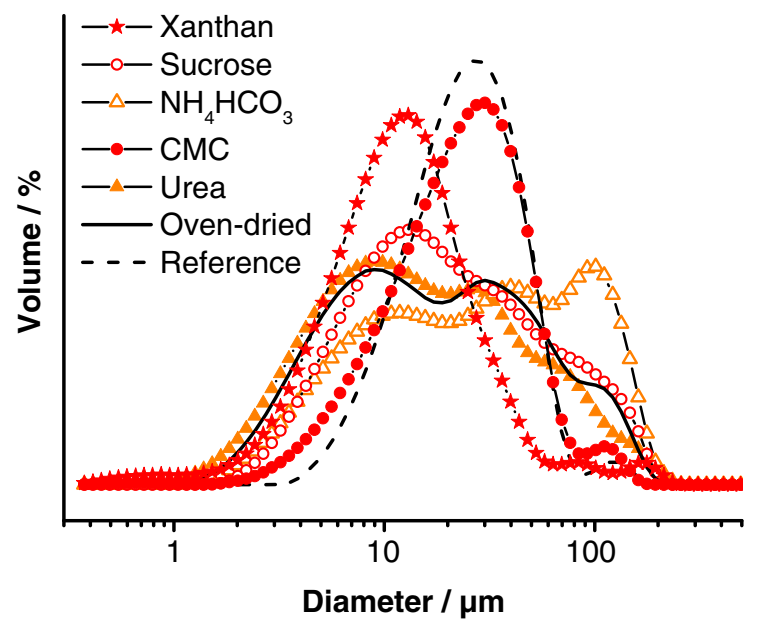

Fig. 5 Particle size distribution of oven-dried redispersed sample in water with and without different additives

increasing shear rate meaning the samples are shearthinning. According to e.g. Butchosa and Zhou (2014), drying and redispersion of nanocelluloses reduces the viscosity with respect to the never-dried sample; this is also shown especially in Fig. 7a. Keeping this in mind, the aim of this study can also be formulated as to reduce this effect on the viscosity and to obtain a redispersed sample with a viscosity similar to the never-dried one.

The shear-thinning curves of the never-dried sample featured a plateau (highlighted in red in Fig. 7a) at a shear rate of approx. $10 \mathrm{~s}^{-1}$ caused by the breaking down of particle aggregates (Beaumont et al. 2016c). This plateau was also observed in the redispersed samples in Fig. 7a, but was less significant and shifted to lower shear rates. In addition to this, the redispersed sample after oven-drying without additive at $60{ }^{\circ} \mathrm{C}$ featured a viscosity of only $0.25 \mathrm{Pas}$ at a shear rate of $0.1 \mathrm{~s}^{-1}$, which is 16 times lower compared to the never-dried sample. Addition of urea and PEG as additives even decreased the viscosity further to 0.09 and 0.04 Pas. At higher shear rates, above $300 \mathrm{~s}^{-1}$, the viscosity of the ovendried samples in Fig. 7a showed shear-thickening behavior due to their heterogeneous particle size distribution (see Fig. 6). In comparison to this, the viscosity of the redispersed xanthan and CMC sample was only reduced by a factor of 2 in comparison to the respective never-dried sample (Fig. 7b). Hence, the addition of xanthan and CMC preserves very well the rheological properties after 


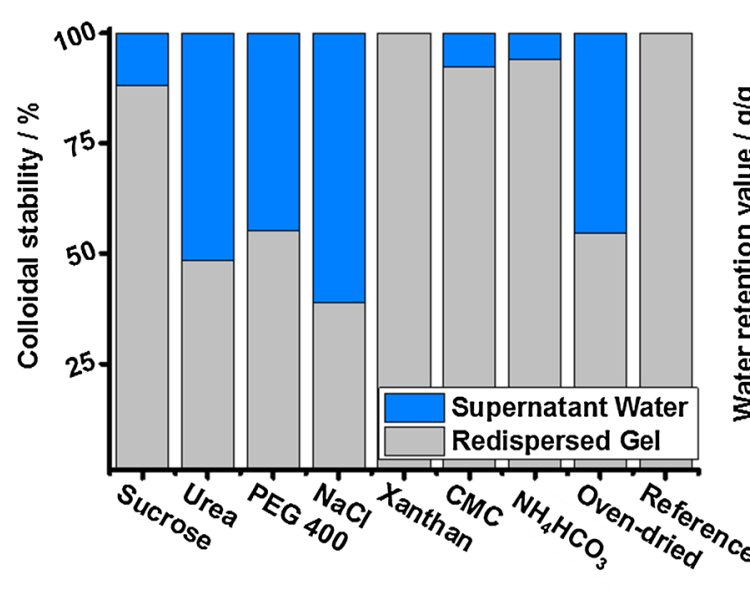

Fig. 6 Left: colloidal stability in water of oven-dried samples with and without additives, after redispersion to a concentration of $1 \mathrm{wt} \%$. Right: water retention values of the redispersed

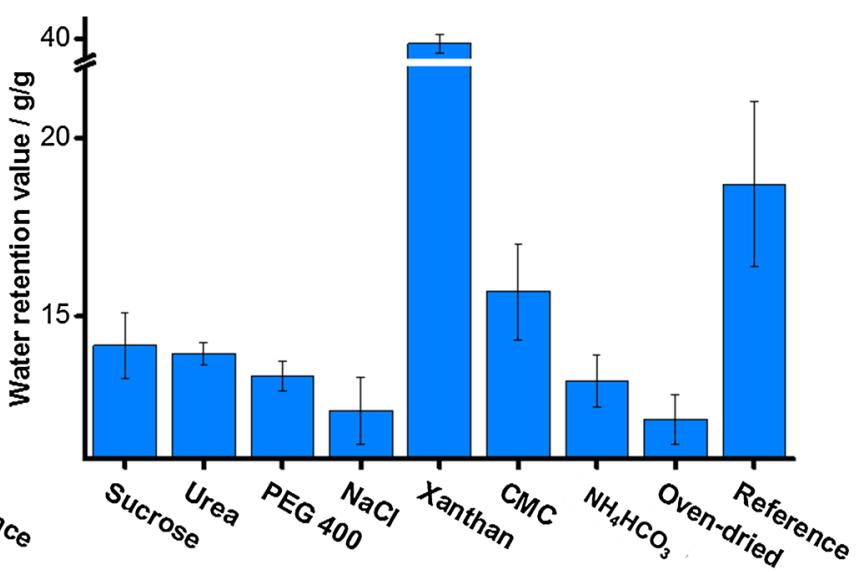

cryogels. The oven-dried sample is listed as comparison, and the reference is the never-dried gel
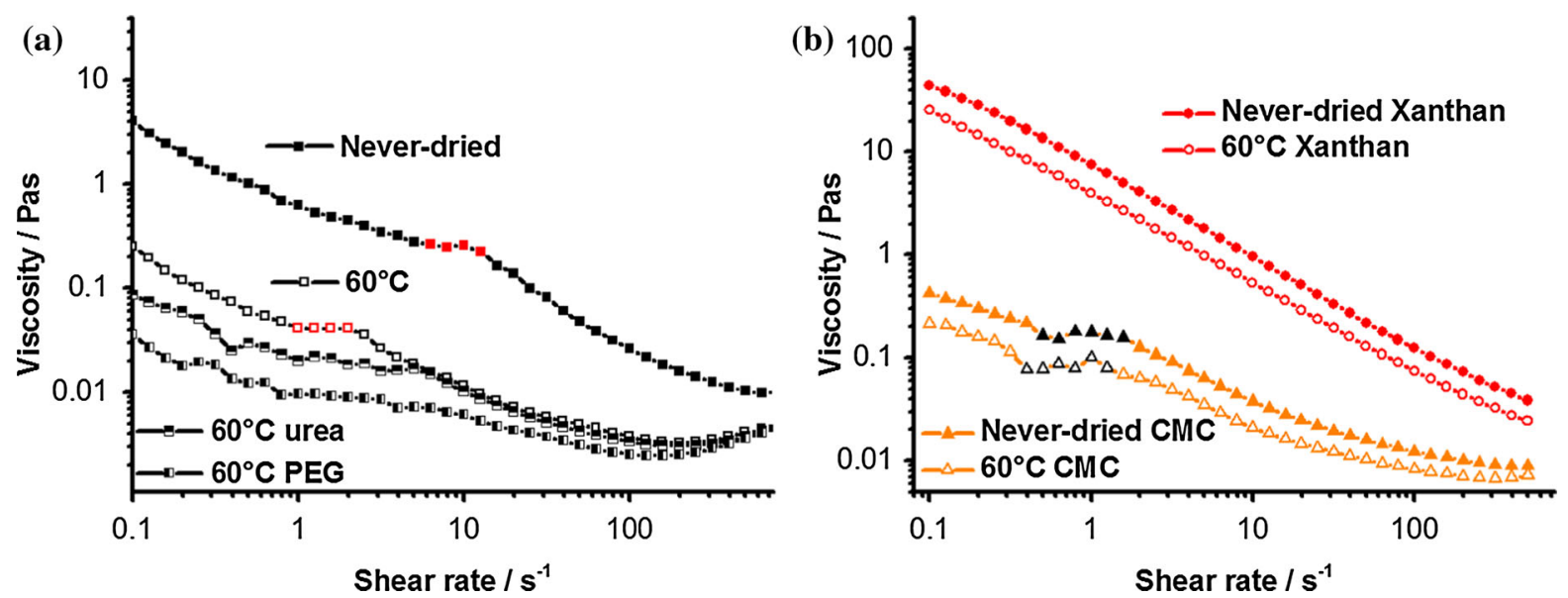

Fig. 7 Comparison of shear-thinning curves of redispersed oven-dried and never-dried samples (1 wt\%) in water. Plateaus in the viscosity curves are highlighted in red (left) or black (right figure) color. (Color figure online)

drying, especially if compared to the dried native sample and the sample with PEG and urea of which the viscosity was reduced by much higher factors.

As expected the addition of a xanthan, which is a strong thickening agent (Symes 1980), increased the viscosity of the cellulose gel significantly. The respective dried and never-dried sample featured an almost linear viscosity reduction for increasing shear rate in the double logarithmic graph (Fig. 7b). In contrast to this, the addition of CMC decreased the viscosity of the cellulose II gel at low shear rates; this was reported as well for CNF/CMC mixtures (Kumar et al. 2016). CMC is prone to adsorb onto cellulose fibrils (Filpponen et al. 2012; Butchosa and Zhou
2014) and thereby seems to reduce the particleparticle interactions in the cellulose II gel, which explains the lower viscosity and the viscosity plateau being shifted to lower shear rates as compared to the never-dried cellulose II gel (Fig. 7a).

\section{Conclusions}

In the present study, first the effect of freeze-drying and oven-drying on TENCEL ${ }^{\circledR}$ gel and CNF with regard to redispersibility and colloidal stability was studied. Freeze-drying is the superior method in case of $\mathrm{CNF}$ with regard to redispersibility. The CNF 
structure is less sensitive towards different freezedrying protocols than the TENCEL ${ }^{\circledR}$ gel, in the case of which different freezing temperatures had a quite dramatic effects, so that the cryogel morphology could be tailored from a sheet-like structure $\left(\mathrm{FD}-20{ }^{\circ} \mathrm{C}\right)$ to highly porous aerogels with preserved micro- and nanostructure (FD tert-BuOH). However, colloidal stability and the WRV of the freeze-dried cellulose II gel were inferior in comparison to samples obtained from mild and simple oven-drying at $60{ }^{\circ} \mathrm{C}$, which for the cellulose II gel was clearly the better-and not only easier-method. Different additives to the cellulose II gel during drying were tested aiming at a possible enhancement of the redispersibility of the respective oven-dried xerogels. Small organic compounds and salts had little effect on the redispersibility. Addition of xanthan and CMC reduced the aggregation and hornification effects and yielded fully redispersible suspensions with particle size, colloidal stability and rheological properties comparable to the never-dried gel.

Freeze-drying protocols using tert-BuOH solvent exchange are only necessary if one aims at preserving the micro- and nanostructure and the high surface area of the cellulose II gel through the dried state. Just to obtain a redispersible gel, oven-drying at $60{ }^{\circ} \mathrm{C}$ with prior addition of xanthan or CMC as additive is the more suitable, far easier and thus recommendable method.

Acknowledgments Open access funding provided by University of Natural Resources and Life Sciences Vienna (BOKU). The project is financed in the framework of the Ph.D. School DokIn'Holz funded by the Austrian Federal Ministry of Science, Research and Economy and Lenzing AG.

Open Access This article is distributed under the terms of the Creative Commons Attribution 4.0 International License (http:// creativecommons.org/licenses/by/4.0/), which permits unrestricted use, distribution, and reproduction in any medium, provided you give appropriate credit to the original author(s) and the source, provide a link to the Creative Commons license, and indicate if changes were made.

\section{References}

Beaumont M, Kondor A, Plappert S et al (2016a) Surface properties and porosity of highly porous, nanostructured cellulose II particles. Cellulose. doi:10.1007/s10570-016$1091-y$
Beaumont M, Nypelö T, König J et al (2016b) Synthesis of redispersible spherical cellulose II nanoparticles decorated with carboxylate groups. Green Chem 18:1465-1468. doi:10.1039/C5GC03031E

Beaumont M, Rennhofer H, Opietnik M et al (2016c) Nanostructured cellulose II gel consisting of spherical particles. ACS Sustain Chem Eng 4:4424-4432. doi:10. 1021/acssuschemeng.6b01036

Butchosa N, Zhou Q (2014) Water redispersible cellulose nanofibrils adsorbed with carboxymethyl cellulose. Cellulose 21:4349-4358. doi:10.1007/s10570-014-0452-7

Cai H, Sharma S, Liu W et al (2014) Aerogel microspheres from natural cellulose nanofibrils and their application as cell culture scaffold. Biomacromolecules. doi:10.1021/ bm5003976

Eichhorn SJ, Dufresne A, Aranguren M et al (2009) Review: current international research into cellulose nanofibres and nanocomposites. J Mater Sci 45:1-33. doi:10.1007/ s10853-009-3874-0

Eyholzer C, Bordeanu N, Lopez-Suevos F et al (2010) Preparation and characterization of water-redispersible nanofibrillated cellulose in powder form. Cellulose 17:19-30. doi:10.1007/s10570-009-9372-3

Filpponen I, Kontturi E, Nummelin S et al (2012) Generic method for modular surface modification of cellulosic materials in aqueous medium by sequential "click" reaction and adsorption. Biomacromolecules 13:736-742. doi: $10.1021 / \mathrm{bm} 201661 \mathrm{k}$

Giacomozzi DE, Joutsimo O (2015) Drying temperature and hornification of industrial never-dried pinus radiata pulps. 1. Strength, optical, and water holding properties. BioResources 10:5791-5808. doi:10.15376/biores.10.3.57915808

Han J, Zhou C, Wu Y et al (2013) Self-assembling behavior of cellulose nanoparticles during freeze-drying: effect of suspension concentration, particle size, crystal structure, and surface charge. Biomacromolecules 14:1529-1540. doi:10.1021/bm4001734

Hettegger H, Beaumont M, Potthast A, Rosenau T (2016) Aqueous modification of nano- and microfibrillar cellulose with a click synthon. ChemSusChem 9:75-79. doi:10. 1002/cssc. 201501358

Hubbe MA, Venditti RA, Rojas OJ (2007) What happens to cellulosic fibers during papermaking and recycling? A review. BioResources 2:739-788

Jayme G (1944) Mikro-Quellungsmessungen an Zellstoffen. Wochenbl Papierfabr 6:187-194

Jiang F, Hsieh Y-L (2014a) Amphiphilic superabsorbent cellulose nanofibril aerogels. J Mater Chem A 2:6337-6342. doi:10.1039/C4TA00743C

Jiang F, Hsieh Y-L (2014b) Assembling and redispersibility of rice straw nanocellulose: effect of tert -butanol. ACS Appl Mater Interfaces 6:20075-20084. doi:10.1021/am505626a

Kekäläinen K, Liimatainen H, Illikainen M et al (2014) The role of hornification in the disintegration behaviour of TEMPOoxidized bleached hardwood fibres in a high-shear homogenizer. Cellulose 21:1163-1174. doi:10.1007/ s10570-014-0210-x

Klemm D, Kramer F, Moritz S et al (2011) Nanocelluloses: a new family of nature-based materials. Angew Chem Int Ed 50:5438-5466. doi:10.1002/anie.201001273 
Kumar V, Elfving A, Koivula H et al (2016) Roll-to-roll processed cellulose nanofiber coatings. Ind Eng Chem Res 55:3603-3613. doi:10.1021/acs.iecr.6b00417

Lavoine N, Desloges I, Dufresne A, Bras J (2012) Microfibrillated cellulose-Its barrier properties and applications in cellulosic materials: a review. Carbohydr Polym 90:735-764. doi:10.1016/j.carbpol.2012.05.026

Männer J, Opietnik M, Innerlohinger J et al (2015) Cellulose suspension, method for the production and use thereof. International patent WO/2015/054712

Müller A, Zink M, Hessler N et al (2014) Bacterial nanocellulose with a shape-memory effect as potential drug delivery system. RSC Adv 4:57173-57184. doi:10.1039/ C4RA09898F

Nemoto J, Saito T, Isogai A (2015) Simple freeze-drying procedure for producing nanocellulose aerogel-containing, high-performance air filters. ACS Appl Mater Interfaces 7:19809-19815. doi:10.1021/acsami.5b05841

Rey L, May JC (2011) Freeze drying/lyophilization of pharmaceutical and biological products. Informa Healthcare, New York, London
Saito T, Kimura S, Nishiyama Y, Isogai A (2007) Cellulose nanofibers prepared by TEMPO-mediated oxidation of native cellulose. Biomacromolecules 8:2485-2491. doi:10. 1021/bm0703970

Smook GA (1990) Handbook of pulp \& paper terminology. Angus Wilde Publications, Vancouver

Symes KC (1980) The relationship between the covalent structure of the Xanthomonas polysaccharide (Xanthan) and its function as a thickening, suspending and gelling agent. Food Chem 6:63-76. doi:10.1016/03088146(80)90007-2

Tingaut P, Eyholzer C, Zimmermann T (2011) Functional polymer nanocomposite materials from microfibrillated cellulose. In: Hashim A (ed) Advances in nanocomposite technology. InTech, Croatia

Weise U, Maloney T, Paulapuro H (1996) Quantification of interaction of water in different states with wood pulp fibres. Cellulose 3:189-202 